\title{
2D-Finite element analysis of inlay-, onlay bridges with using various materials
}

\author{
B. Śmielak a, J. Świniarski b, E. Wołowiec-Korecka c, ${ }^{\star}$, L. Klimek c,d \\ a Department of Prosthodontics, Medical University of Lodz, \\ ul. Pomorska 251, 92-213 Łódź, Poland \\ b Department of Strength of Materials of the Technical University of Lodz, \\ ul. Stefanowski 1/15, 90-924 Łódź, Poland \\ c Institute of Material Science and Engineering, Lodz University of Technology, \\ ul. Stefanowski 1/15, 90-924 Łódź, Poland \\ d Department of Dental Techniques, Medical University of Lodz, \\ ul. Pomorska 251, 92-231 Łódź, Poland \\ * Corresponding e-mail address: emilia.wolowiec@p.lodz.pl
}

\section{ABSTRAGT}

Purpose: To compare the impact of different bridge constructions and different loads on stress distribution in bridges.

Design/methodology/approach: The study was conducted on 96 computer models of both premolars and molars that simulated a missing second premolar restored with a bridge supported on crown inlays or onlays. Simulations were made of a bridge constructed from four different materials: Au alloy, Cr/Ni alloy as well as two kinds of glass fibre-reinforced composites: Targis Vectris and FibreKor /Sculpture. The study was conducted using the finite element method (FEM). The results were analysed with PQStat statistical software version 1.6.

Findings: In none of the analysed cases did stresses appear capable of damaging the bridge construction. Reduced stresses were lower in glass fibre reinforced composite materials than in metal alloys.

Practical implications: The force application point has a decisive influence on stress distribution in the hard dental tissue and in bridges. The highest stress values occurred at the loading of the pontic tooth.

Originality/value: The force application point has a decisive influence on stress distribution in the hard dental tissue and in bridges. The highest stress values occurred at the loading of the pontic tooth.

Keywords: Numerical techniques; FEM; Adhesive bridges; FRC composites

Reference to this paper should be given in the following way:

B. Śmielak, J. Świniarski, E. Wołowiec-Korecka, L. Klimek, 2D-Finite element analysis of inlay-, onlay bridges with using various materials, Archives of Materials Science and Engineering 79/2 (2016) 71-78. 


\section{Introduction}

Resin-bonded fixed partial dentures (RBFPD) have been accepted as a significant means of replacing missing teeth in prosthodontics since Rochette introduced this concept in 1973 and have now been extended from anterior teeth to the posterior regions of the jaw, with their heavier occlusal demands [1-9]. They are usually used in implantology during periods of bone regeneration or implant osseointegration [10-12].

Adhesive bridges can be made on a metal alloy substructure veneered with a composite, a ceramic or with glass fibre reinforced composites (FRC). Prosthetic treatment involving the use of adhesive bridges is still a cause of some concern in dental practice as the method involves some risk of failure.

However, more complicated geometry and design structure, low retention rate of RBFPD, in contrast to conventional fixed partial dentures (FPD), is still a vital issue in prosthetic dentistry. The low retention rate between the retainer and abutment tooth usually causes interface debonding between metal and abutment teeth after under repeated loading during long- term use [13-19, 3-9]. In order to provide superior bonding strength and reduce the stress at the prosthesis/abutment teeth interface, many studies have presented several effective techniques to improve the adhesive agents or new materials instead of the original rigid metal retainers [15-26]. However, clinical experience still shows unsatisfactory survival rate (only $40 \%$ ) for mandibular RBFPD prostheses [15-17,19,21,22]. The most common cause of failure in bridges made from FRC type materials is fracturing of the pontic and separation of the veneering composite from the fibres [13]. The survival rate for bridges on a metal alloy substructure is $25 \%$ after 15 months, while the 5 -year survival rate for FRCs is $87.7-64 \%$ [25-30].

Adhesive bridges can be made on a metal alloy substructure veneered with a composite, a ceramic or with glass fibre reinforced composites (FRC). The present study compared the reduced stresses that occur in bridges made from different materials supported on inlays or onlays.

\section{Material and methods}

\subsection{Material}

The study was carried out on 96 computer models of mandibular premolars and molars simulating a missing second premolar that was restored with a bridge supported on inlays or onlays. A simulation was made of a bridge constructed from four different dental materials: gold alloys, chrome-nickel alloys, Targis /Vectris glass-fibre reinforced composites (Ivoclar, Schaan; FL Lichtenstein), and FibreKor/Sculpture glass-fibre reinforced composites (Jeneric/Pentron, Wallingford, CT; USA).

Table 1 presents the mechanical properties of the materials used for numerical analysis [31-33]. Each model was subjected to four loading variants with forces of 200 $\mathrm{N}$ : in variant one the force was applied in equal measure to the crown cusps and the centre of the occlusal surface of the pontic; in variant two the force was applied at the tip of the cusp of the first premolar; in variant three the force was applied to the centre of the occlusal surface of the pontic, while in the fourth variant the force was applied to the tips of the cusps of the first molar. These are the mean forces that occur during mastication in the region of the molars and premolars in patients with fixed prosthetic restorations [34].

Tensile strength $\left(\mathrm{R}_{\mathrm{m}}\right)$ is the highest stress value corresponding to the greatest force achieved during a trial, in relation to the initial surface size [31].

Distinct yield point $(\mathrm{Re})$ is the stress at which a distinct extension in the stretched sample occurs without any increase or even with a decline in loading [31].

Compressive strength $\left(\mathrm{R}_{\mathrm{c}}\right)$ is the ratio of the greatest loading force resulting in damage (crumbling or cracking) to the sample in relation to its original cross-sectional area [31].

\subsection{Methods}

The study was conducted according to the finite element method (FEM) using a flat, two-dimensional model of abutment teeth and a fixed restoration created on an ATHLON 1500 XP computer with the ANSYS 10 (ANSYS v. 10; ANSYS Inc., Canonsburg, PA, USA) [35]. Two-dimensional models of mandibular premolars and first molar were produced on the basis of anatomical data taken from the literature [36]. For calculation purposes the model was divided into 220,000 finite elements. Selected coordinates of point outlining the tooth projections on the $\mathrm{XY}$ plane were entered in the $\mathrm{XY}$ axis configuration into the computer programme. Appropriate points were joined together with lines. These lines formed the base for creating surfaces. In this way a flat, two-dimensional model was formed that reflected the shape and dimensions of the teeth. The first premolar possessed the following dimensions of a crown: length: $22.5 \mathrm{~mm}$, width $7 \mathrm{~mm}$ on the circumference, which narrowed around the cervix area to $5 \mathrm{~mm}$, while the root was $14 \mathrm{~mm}$ in length and surrounded by periodontal ligaments $0.2 \mathrm{~mm}$ in width. 
Table 1.

Mechanical properties of materials used for FEM calculations, MPa

\begin{tabular}{cccccc}
\hline Material & Young's modulus, MPa & Poisson's ratio $v,-$ & $\mathrm{R}_{\mathrm{m}}, \mathrm{MPa}$ & $\mathrm{R}_{\mathrm{e}}, \mathrm{MPa}$ & $\mathrm{R}_{\mathrm{c}}, \mathrm{MPa}$ \\
\hline Gold alloy & $7.5 \cdot 10^{4}$ & 0.3 & $414-828$ & $207-620$ & --- \\
\hline Cr-Ni alloy & $2.4 \cdot 10^{4}$ & 0.33 & 421 & 359 & --- \\
\hline Targis/ Vectris Pontic & $1.55 \cdot 10^{4}$ & 0.3 & 700 & --- & --- \\
\hline Targos/Vectris Frame & $4.88 \cdot 10^{3}$ & 0.31 & 1300 & --- & --- \\
\hline FibreKor/ Sculpture & $1.15 \cdot 10^{4}$ & 0.3 & 938 & --- & --- \\
\hline Composite & $1.37 \cdot 10^{3}$ & 0.35 & 142 & --- & --- \\
\hline Enamel & $8.4 \cdot 10^{4}$ & 0.33 & 11.5 & --- & 384 \\
\hline Dentine & $1.86 \cdot 10^{4}$ & 0.31 & 105.5 & --- & 297.0 \\
\hline Periodontium & 68.9 & 0.45 & --- & --- & --- \\
\hline Cortical bone & $1,1 \cdot 10^{4}$ & 0.3 & --- & --- & --- \\
\hline Cancellous bone & 1370 & 0.3 & --- & --- & --- \\
\hline Resin cement & 2400 & 0.4 & 50 & --- & $220-300$ \\
\hline Phosphate cement & $2.24 \cdot 10^{4}$ & 0.25 & $3-5$ & --- & $96-130$ \\
\hline
\end{tabular}

The tooth in the pontic possessed the following dimensions: length: $8.5 \mathrm{~mm}$, width $7 \mathrm{~mm}$ on the circumference, and $5 \mathrm{~mm}$ in the cervical area. The first molar had the following parameters: length: $20 \mathrm{~mm}$, width $10 \mathrm{~mm}$, narrowing in the cervical area to $8 \mathrm{~mm}$, the roots: length 12 and $13 \mathrm{~mm}$, respectively, and surrounded by periodontal ligaments $0.2 \mathrm{~mm}$ in width. Computer models were fixed in places coinciding with actual tooth supports. Static loading was applied. Forces of specific value and direction were applied to the nodes. In each variant, we considered a bridge construction supported on inlays and onlays. In each case simulations were made of a bridge made from four different dental materials: It was assumed that the materials forming the model are isotropic and with linear-elastic mechanical characteristics (Figs. 1,2).

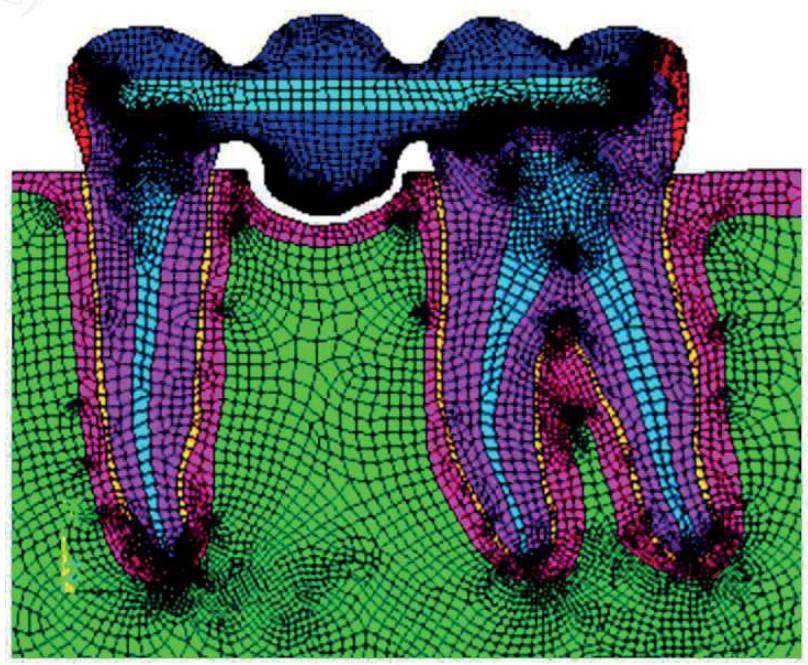

Fig. 1. Construction supported on inlays

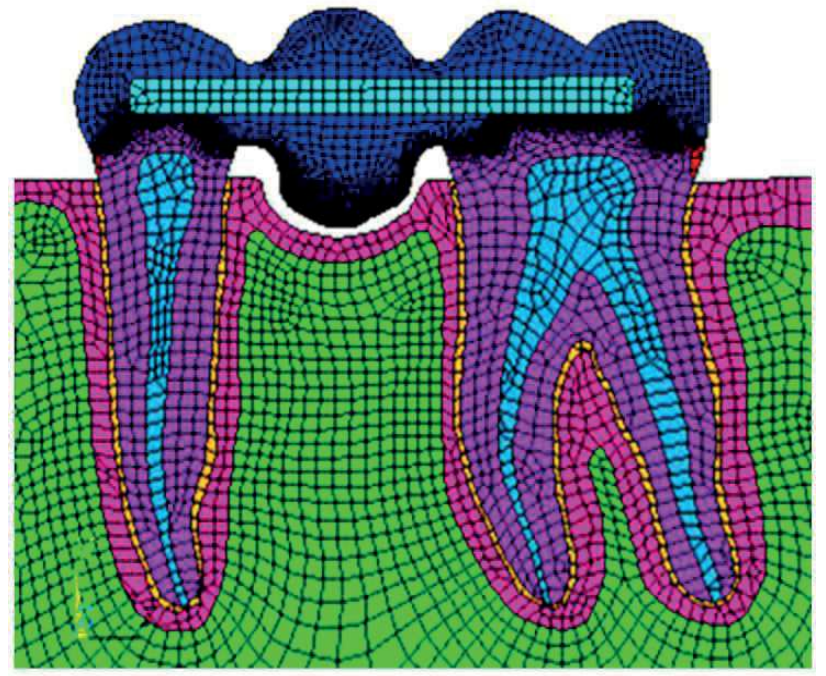

Fig. 2. Construction supported on onlays

The results were analysed using PQStat statistical software ver. 1.6.

The differences between the results for the inlays and onlays were analysed using the Student's t-test for dependent variables as well as the Hotelling's multidimensional test.

Test probability was regarded as significant at $\mathrm{p}<.05$, and as highly significant at $\mathrm{p}<.01$.

\section{Results}

The results were presented in the form of colour maps of normal stresses $\sigma_{\mathrm{x}}, \sigma_{\mathrm{y}}$, and reduced stresses $\sigma_{\text {red }}$ according to the Huber-Mises-Hencky hypothesis. These 
stresses are calculated according to the strength hypothesis of shear-deformation energy for complex stress conditions, which are as dangerous for a given material as those stresses that occur with simple stretching. In the case of isotropic materials with linear mechanical characteristics, these stress values indicate the material straining (i.e. the stress conditions in the material that create a risk of material damage occurring) [37]. The colour code, ranging from navy blue to red in the computer printout legend, accords with an increase in stress values. Identical colouring in a given area of the mathematical model indicates approximately the same stress value there.

\subsection{Comparison of stress distribution in bridges depending on the material used and the construction}

Figures 3 and 4 compare reduced stresses in bridges made from $\mathrm{Au}$ and $\mathrm{Cr}-\mathrm{Ni}$ alloys as well as FibreKor/ Sculpture and Targis/Vectris composite materials supported on inlays and onlays. Tensile strength $\left(\mathrm{R}_{\mathrm{m}}\right)$ for gold alloy is $207 \mathrm{MPa}$, for Cr-Ni alloy is $359 \mathrm{MPa}$, for Sculpture composite is $142 \mathrm{MPa}$, for Fibre/Kor fibres is $938 \mathrm{MPa}$, for Targis composite is $140 \mathrm{MPa}$, for Vectris Pontic and Frame fibres is $1000 \mathrm{MPa}$ [31].

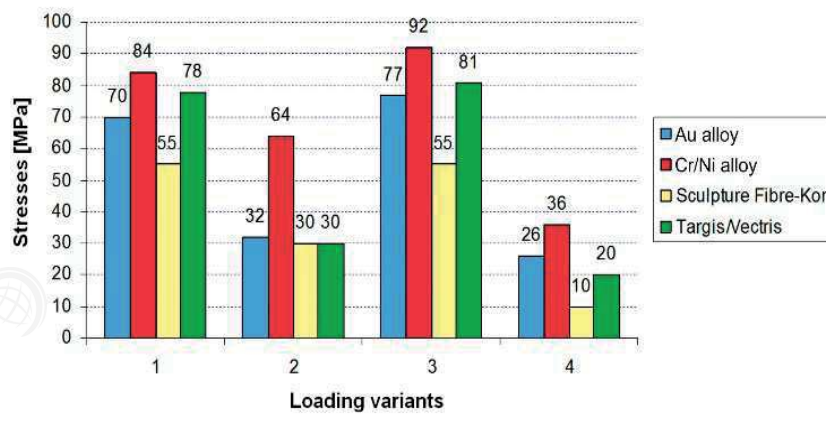

Fig. 3. Construction supported on inlays, Stresses in bridge

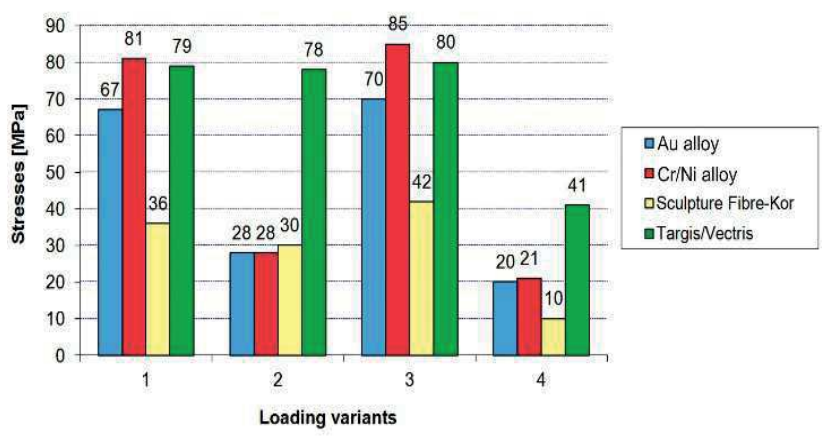

Fig. 4. Construction supported on onlays, Stresses in bridge
The Student's t-test for dependent variables comparing the results presented in diagrams 5 and 6 indicate no significant difference $-\mathrm{t}=0.60, \mathrm{df}=15, \mathrm{p}=0.5584$.

Additionally, a Hotelling's three-dimensional test was performed on three parameters, i.e. dentine, enamel and tensile strength. It showed no significant difference between constructions supported on inlays and onlays $\left.\mathrm{T}^{\wedge} 2=2.07, \mathrm{~F}=0.60, \mathrm{df} 1=3, \mathrm{df} 2=13, \mathrm{p}=0.6274\right)$. In all these cases stress concentrations did not exceed the tensile strength for the materials used in the study.

\subsection{Comparison of stress distribution in the hard tissue of teeth in bridges depending on the loading method}

No statistically significant difference was observed between constructions supported on inlays and onlays $\mathrm{t}=1.30, \quad \mathrm{df}=3, \mathrm{p}=0.2850$ ). Stress concentrations were observed in dentine at the height of the neck of the first premolar in the case of the bridge construction supported on onlays (Fig. 5) as well as at the border between the tooth in the pontic and the inlays (Fig. 6).

No significant difference was observed between constructions supported on inlays and onlays - $\mathrm{t}=0.24$, $\mathrm{df}=3, \mathrm{p}=0.8236$ ). Concentrations mainly appeared at the mesial tangent of the root of the first premolar as well as in the gingival area at the border of the pontic tooth and the onlay supported on the first molar (Figs. 7,8).

A significant difference was observed between constructions supported on inlays and onlays - $\mathrm{t}=3.22$, $\mathrm{df}=3, \mathrm{p}=0.0485$, i.e. higher results after using inlay-based constructions. Concentrations occurred at the border of the pontic tooth and the inlays (Figs. 9,10).

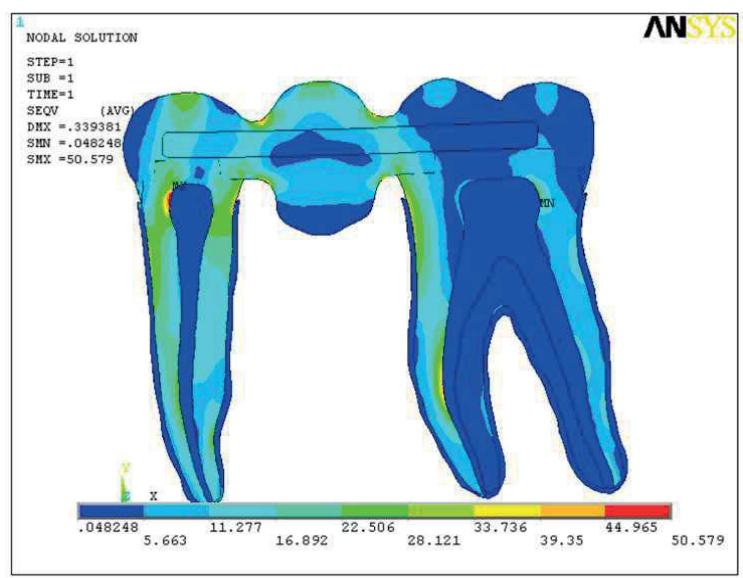

Fig. 5. A bridge made out of FibreKor/Sculpture material supported on onlays 


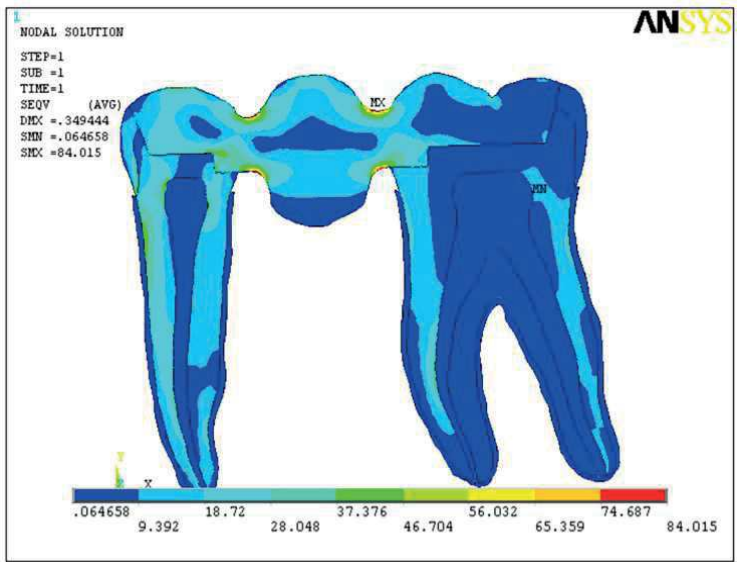

Fig. 6. A bridge made out of $\mathrm{Ni} / \mathrm{Chr}$ alloy supported on inlays

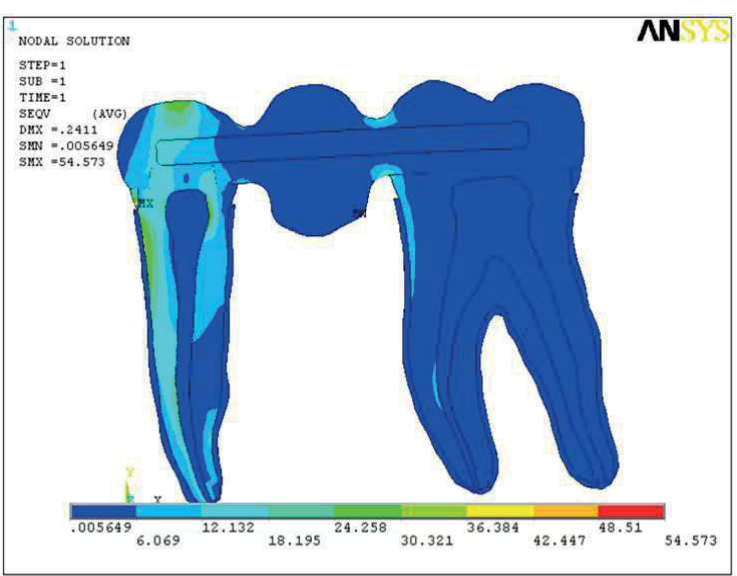

Fig. 7. A bridge made out of FibreKor/Sculpture material supported on onlays

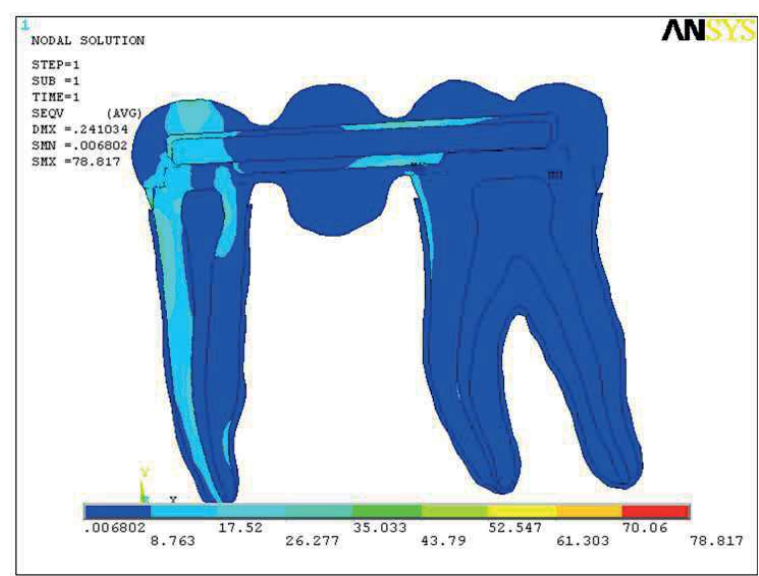

Fig. 8. A bridge made out of Targis/Vectris material supported on onlays

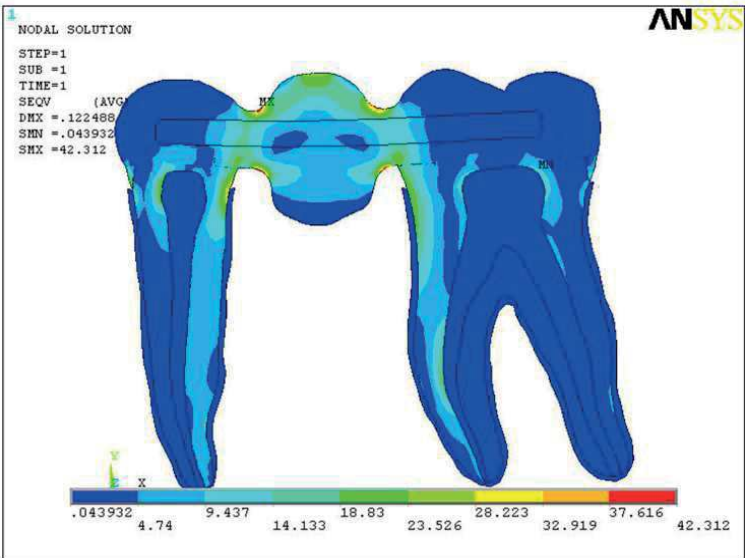

Fig. 9. A bridge made out of FibreKor/Sculpture material supported on onlays

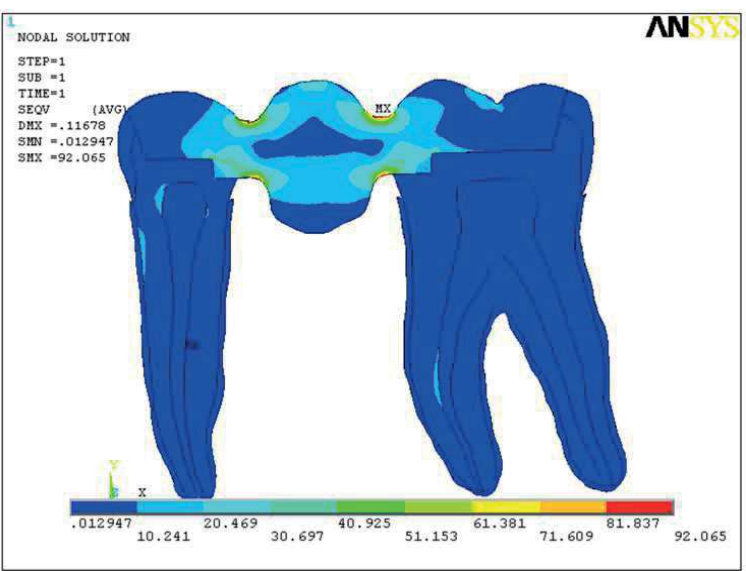

Fig. 10. A bridge made out of $\mathrm{Ni} / \mathrm{Chr}$ alloy supported on crown inlays

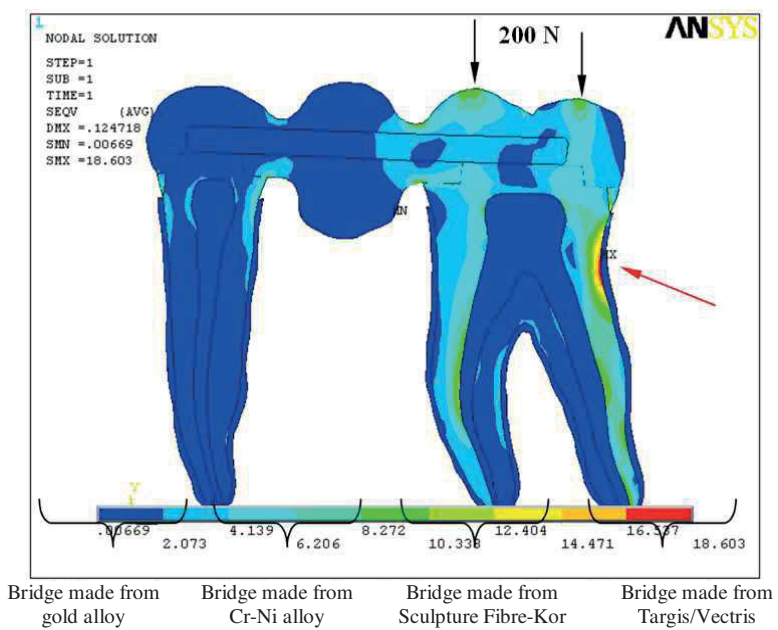

Fig. 11. A bridge made out of FibreKor/Sculpture material supported on onlays 
No significant difference was observed between constructions supported on inlays and onlays $-\mathrm{t}=-0.06$, $\mathrm{df}=3, \mathrm{p}=0.9530$ ). Concentrations appeared on the distal tangent of the distal root of the first molar (Figs. 11,12).

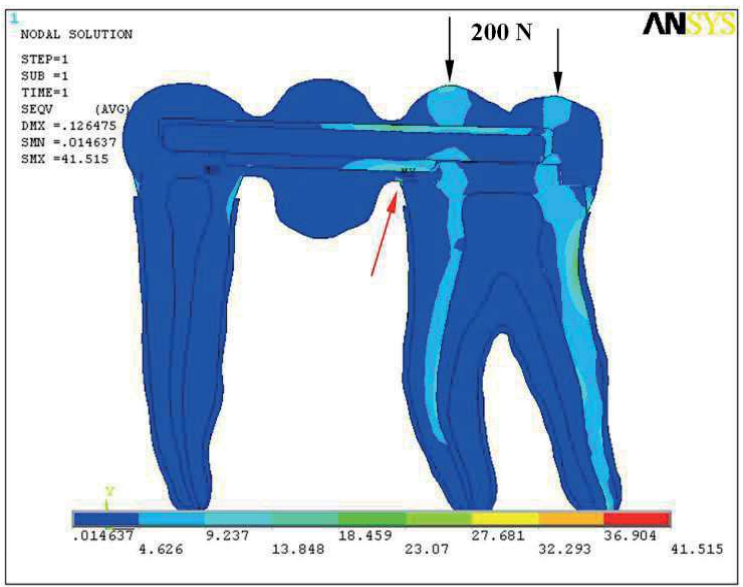

Fig. 12. A bridge made out of Targis/Vectris material supported on onlays

\section{Discussion}

Strength testing cannot be performed on teeth in the oral cavity as this could lead to tissue damage. The twodimensional FEM method was employed in the present study. The scale of the problem addressed in the study did not allow for a solid model. Hence, the focus was on a twodimensional model. The compliance of FEM test results with actual conditions depends among other things on there being agreement between the shape, dimension and material data and loading character of the model on the one hand and the values observed in the studied construction on the other. The shape and dimensions of the model were a reproduction of average, standard mandibular molars and premolars as set down in Wheeler's "Atlas of Tooth Form" [36]. The values for Young's modulus and Poisson's ratio for the materials used in the model were taken from the literature [31-33]. In the specialist literature the same numerical values are repeated for the majority of the materials. On the other hand, although many studies have focused on the problem of studying the physical properties of the compact and cancellous bone, the reported values for these tissues vary significantly [37-39]. The values reported in the literature vary depending on whether the studies were performed on fresh or dried samples, as well as on the kind of bone used (femur, humerus, etc.), the physical condition of the donor and the age of the patients [40]. Bearing in mind these facts we adopted those values presented by Ho Ming-Hsun [32] in a study on the mandibular bone, i.e. compact bone $\mathrm{E}=1370$
$\mathrm{MPa}, \mathrm{v}=0.3$, cancellous bone $\mathrm{E}=1370 \mathrm{MPa}, \mathrm{v}=0.3$. The values for Young's modulus and Poisson's ratio for Sculpture Fibre-Kor and Targis-Vectris were obtained from the manufacturers and literature [33].

In the FEM tests it was assumed that the materials used in models would be homogenous (they had a homogenous structure), isotropic (they exhibited the same mechanical properties in all directions), and had linear-elastic properties. This means that the stress values in these materials were proportional to any strain or deformation. In reality, the materials present in teeth with cemented bridges do not possess a uniform structure. The majority of the materials from which teeth are constructed have anisotropic properties: e.g. dentine, on account of its tubular morphological structure, and enamel, owing to its prismatic structure. They have different tensile and compression strengths. Their mechanical characteristics are nonlinear. In the FEM tests it was assumed that the connection between the different materials from which teeth restored with inlays or onlays are constituted was ideal and remained undamaged despite any increase in loading. In actual fact, there is no clinically ideal connection between fixed prosthetic restorations and the hard dental tissue. This is due to the imprecision of laboratory production and the limited tensile strength of the majority of bonding cements [41].

The models were subjected to loading with a vertical force of $200 \mathrm{~N}$ applied to different places on the occlusal surface of the bridges. Masticatory forces are difficult to measure, but maximum bite force is useful as a basic parameter. Its value is dependent on the kind of prosthetic restoration used as well as on whether the opposing teeth are natural or not. Besides these factors, the impact of masticatory forces on teeth in the oral cavity varies over time, which results in material fatigue (a decline in strength with changeable stresses). Recreating actual loading occurring in the oral cavity is difficult in laboratory conditions [42]. The majority of studies were conducted in static conditions.

FEM-based calculations reveal a difference in tensile stresses at the border between the restoration and dental tissue when using materials with the highest and lowest elastic modulus values. A low composite cement module may result in temporary displacement of the restoration. This concerns in particular the approximal parts of restorations, which may break off from the axial wall of the tooth. Such a phenomenon was observed in a pontic tooth loaded in a bridge (the third loading variant). The subsequent release of these forces results in the restoration returning to its position, but this may have the effect of weakening the connection with the dental tissue, which is reflected in microleakage and secondary caries. However, it is important to stress that resinous cements have a fairly 
high tensile strength value (50 MPa) and a relatively low Young's modulus when compared with phosphate cements (3-5 MPa), which have a significantly higher (around 100 times greater) Young's modulus. For this very reason, the use of phosphate cements to place prosthetic restorations made from metal alloy may lead to a loss of connection.

The use of stronger and less soluble cements appears necessary to reduce the number of clinical failures. It is very important to ensure that the enamel surfaces of abutment teeth are properly prepared and the metal surface suitably conditioned. Inappropriate preparation of these surfaces increases the danger of gaps appearing at the margins of the restoration. Using three-dimensional (3D) FE technology could permit detailed assessment of the mechanical responses to alternations of biomechanical parameters. Despite the advantages of the FE technology, the $3 \mathrm{D}$ model is relatively difficult to construct even with a commercial software pack-age $[43,44]$.

FRC materials offer an interesting alternative in selected cases of treatment. Nevertheless, careful consideration should be given to the indications for their use. It is absolutely imperative that the patient be made aware of the danger of swallowing or aspiring a detached restoration. The patient's consent for such treatment and regular follow-up visits is an important precondition for using adhesive bridges.

\section{Conclusions}

A computer simulation of 96 different cases of bridge constructions produced the following conclusions:

- In none of the analysed cases did stresses appear capable of damaging the bridge construction. Reduced stresses were lower in glass fibre reinforced composite materials than in metal alloys.

- The force application point has a decisive influence on stress distribution in the hard dental tissue and in bridges. The highest stress values occurred at the loading of the pontic tooth.

\section{References}

[1] A.L. Rochette, Attachment of a splint to enamel of lower anterior teeth, Journal of Prosthetic Dentistry 30 (1973) 418-423.

[2] M.R. Dimashjieh, A.R. Al-Shammery, Long-term survival of sleeve-designed fixed partial dentures: a clinical report, Journal of Prosthetic Dentistry 84 (2000) 591-593.

[3] A.A. Saad, N. Claffey, D. Byrne, D. Hussey, Effect of groove placement on retention/resistance of maxillary anterior resin-bonded retainers, Journal of Prosthetic Dentistry 74 (1995) 133-139.
[4] T.A. Imbery, E.G. Eshelman, Resin-bonded fixed partial den- tures: a review of three decades of progress, The Journal of the American Dental Association 127 (1996) 751-760.

[5] R. Stockholm, F. Isidro, Resin-bonded inlay retainer pros- theses for posterior teeth. A 5-year clinical study, International Journal of Prosthodontics 9 (1996) 161-166.

[6] T. Kerschbaum, B. Haastert, C.P. Marinello, Risk of de-bonding in three-unit resin-bonded fixed partial dentures, Journal of Prosthetic Dentistry 57 (1996) 248-253.

[7] A. Mudassir, Y.E. Aboush, M. Hosein, T. Hosein, I. Padihar, Long- term clinical performance of resinbonded fixed partial dentures placed in a developing country, Journal of Prosthodontics 4 (1995) 233-236.

[8] W.P. Saunders, Resin- bonded bridge work: a review, Journal of Dentistry 17 (1989) 255-265.

[9] V.D. Williams, K.E. Thayer, G. Denehy, D.B. Boyer, Cast metal resin-bonded prostheses: a 10-year retrospective study, Journal of Prosthetic Dentistry 61 (1989) 436-441.

[10] C.C. van Heumen, C.M. Kreulen, M.E. Bronkhorst, E. Lesaffre, N.H. Creugers, Fiber-reinforced dental composites in beam testing, Dental Materials 24 (2008) 1435-1443.

[11] O. El-Mowafy, M.H.M. Rubo, Resin-bonded fixed partial dentures: a literature review with presentation of a novel approach. International Journal of Prosthodontics 13/6 (2000) 460-467.

[12] K.A. Durey, P.J. Nixon, S. Robinson, M.F.W.Y. Chan, Resin bonded bridges: techniques for success, British Dental Journal 211/3 (2011) 113-118.

[13] N.H. Creugers, A.F. Kayser, An analysis of multiple failures of resin-bonded bridges, Journal of Dentistry 20 (1992) 348-351.

[14] G. Priest, An eleven-year revaluation of resin-bonded fixed partial dentures, The International Journal of Periodontics and Restorative Dentistry 15 (1995) 239-247.

[15] M. Botelho, Resin-bonded prostheses: the current state of development, Quintessence International 30 (1999) 525-534.

[16] J.F. Simon, R.G. Gartrell, A. Grogono, Improved retention of acid-etched fixed partial dentures: a longitudinal study, Journal of Prosthetic Dentistry 68 (1992) 611-615.

[17] J.D. Duncan, G.W. Reeves, J.G. Fitchie, Adding retention features in the rebonding of cast metal resin-bonded prostheses, Journal of Prosthodontics 2 (1993) 67-69.

[18] O. Hannson, B. Bergstrom, A longitudinal study of resin bonded prostheses. Journal of Prosthetic Dentistry 76 (1996) 132-139. 
[19] K.V. Pekka, S. Camilla, Resin-bonded, glass fiberreinforced composite fixed partial dentures: a clinical study, Journal of Prosthetic Dentistry 84 (2000) 413-418.

[20] C.P. Marinello, T. Kerschbaum, B. Heinenberg, R. Hinz, S. Peters, P. Pfeiffer, P.D. Reppel, H. Schwickerath, Experiences with resin bonded bridges and splints-a retrospective study, Journal of Oral Rehabilitation 14 (1987) 251-260.

[21] R.J. De Kanter, N.H. Creugers, C.W. Verzijden, M.A. van't Hof, A five-year multi-practice clinical study on posterior resin- bonded bridges, Journal of Dental Research 77 (1998) 609-614.

[22] T.N. Göhring, M. Roos, Inlay-fixed partial dentures adhesively retained and reinforced by glass fibres: clinical and scanning electron microscopy analysis after five year, European Journal of Oral Sciences 113/1 (2005) 60-69.

[23] L. Shi, A.L. Fok, Structural optimization of the fibrereinforced composite substructure in a three-unit dental bridge, Dental Materials 25 (2009) 791-801.

[24] D.L. Hussey, C. Pagni, G.J. Linden, Performance of 400 adhesive bridges fitted in a restorative dentistry department, Journal of Dentistry 19 (1991) 221-225.

[25] J.B. Eshleman, P.C. Moon, R.F. Barne, Clinical evaluation of cast metal resin-bonded anterior fixed partial dentures, Journal of Prosthetic Dentistry 51 (1984) 761-764.

[26] L. Yanover, W. Croft, F. Pulver, The acid-etched fixed prosthesis, The Journal of the American Dental Association 104 (1982) 325-328.

[27] G.J. Re, D.A. Kaiser, W.F. Malone, F. Garcia-Godoy, Shear bond strengths and scanning electron microscope evaluation of three different retentive methods for resin-bonded retainers, Journal of Prosthetic Dentistry 59 (1988) 568-573.

[28] B.E. Pjetursson, W.C. Tan, K. Tan, U. Brägger, M. Zwahlen, N.P. Lang, A systematic review of the survival and complication rates of resin-bonded bridges after an observation period of at least 5 year, Clinical Oral Implants Research 19/2 (2008) 131-141.

[29] C.C. van Heumen, J.W. van Dijken, J. Tanner, R. Pikaar, L.V. Lassila, N.H. Creugers, P.K. Vallittu, C.M. Kreulen, Five-year survival of 3-unit fiberreinforced composite fixed partial dentures in the anterior area, Dental Materials 25/6 (2009) 820-827.

[30] D. Yokoyama, A. Shinya, H. Gomi, P.K. Vallittu, Effects of mechanical properties of adhesive resin cements on stress distribution in fiber-reinforced composite adhesive fixed partial dentures, Dental Materials Journal 31/2 (2012) 189-196.
[31] J.M. Powers, R. Sakaguchi, Craig's restorative dental materials. 12th ed., St. Louis, Mosby, 2006.

[32] M.H. Ho, et al., Three-dimensial finite element analysis of the effects of posts on stress distribution in dentine, Journal of Prosthetic Dentistry 72/4 (1994) 367-372.

[33] P. Magne, N. Perakis, U.C. Belser, I. Krejci, Stress distribution of inlay-anchored adhesive fixed partial dentures: a finite element analysis of the influence of restorative materials and abutment preparation design, Journal of Prosthetic Dentistry 87/5 (2002) 516-528.

[34] C. Gibbs, P. Mahan, H. Lundeen, K. Brehnan, E. Walsh, W. Holbrook, Occlusal forces during chewing and swallowing as measured by sound transmission, Journal of Prosthetic Dentistry 46/4 (1981) 443-449.

[35] O.C. Zienkiewicz, R.L. Taylor, J.Z. Zhu, The finite element method, its basis and fundamentals 6th ed., Amsterdam, Elsevier-Butter-worth-Heinemann, 2005, 103-128.

[36] M. Ash, S. Nelson, Wheeler's dental anatomy, physiology and occlusion. 8th ed., Philadelphia, Saunders Co, 2003, 297-314.

[37] R. De Groot, M. Peters, Y. De Haan, G. Dop, A. Plasschaert, Failure stress criteria for composite resin, Journal of Dental Research 66/12 (1987) 1748-1752.

[38] D.T. Reily, A.H. Burstein, The mechanical properties of cortical bone, The Journal of Bone \& Joint Surgery 56/5 (1974) 1001-1022.

[39] J.Y. Rho, R.B. Ashman, C.H. Turner, Young's modulus of trabecular and cortical bone material: ultrasonic and microtensile measurements, Journal of Biomechanics 26/2 (1993) 111-119.

[40] L.M.H. Habets et al., Mandibular atrophy and metabolic bone loss, International Journal of Oral and Maxillofacial Surgery 16 (1987) 540-547.

[41] C.A. Mitchell, J.G. Kennedy, A semi-empirical model for prediction of how post-retained crowns will fail under compressive loading, Journal of Dental Research 71/9 (1992) 1613-1618.

[42] J.F. Orr, C.A. Mitchell, The evaluation of postretained crowns using a custom-designed fatigue machine, Journal of Oral Rehabilitation 23/3 (1996) 179-185.

[43] C.L. Lin, C.H. Chang, C.S. Cheng, H.E. Lee, Threedimensional finite element meshing generation for maxillary second premolar, Computer Methods and Programs in Biomedicine 59 (1999) 187-195.

[44] C.L. Lin, H.E. Lee, C.H. Wang, K.H. Chang. Interfacial stress analysis between posterior resinbonded bridge and abutments by finite element approach, Computer Methods and Programs in Biomedicine72 (2003) 55-64. 